\title{
Das palavras às ações
}

\section{From words to actions}

\section{Senhor editor,}

Bastante interessante o trabalho "Sexual activity among female teenagers: a comparison between two groups of middle class adolescents from a private clinic according to pregnancy status" de Faisal-Cury e Menezes. ${ }^{1}$ Muito nos chamou a atenção, não apenas por ter sido realizado com garotas de classe média e em consultório privativo, clientela pouco estudada em nosso país, como pela conclusão de que o conhecimento sobre técnicas contraceptivas não é suficiente para evitar gestações não planejadas.

Estudo empreendido sobre concepções e práticas relacionadas à sexualidade de adolescentes, em um hospital de ensino em Recife, apresentou resultados semelhantes. ${ }^{2}$ A amostra se compôs de 410 adolescentes de ambos os sexos (63\% feminino), com idade média de 14,6 anos, a maioria pertencente às classes econômicas C e D, com quatro anos a oito anos de estudo, e cujas mães tinham alto grau de analfabetismo funcional, ou seja, 38,5\% com até três anos de estudo. Sabe-se que o grau de instrução materna e o nível de renda familiar diferenciam mulheres de grupos menos privilegiados, que se iniciam mais cedo na via sexual.3,4 A maioria dos 85 adolescentes com vida sexual ativa relatou o condom como principal método anticonceptivo, e $60 \%$ no sexo feminino e $75 \%$ no masculino afirmaram tê-lo usado na última relação sexual. O principal motivo do uso, para ambos os sexos, foi evitar tanto a gravidez quanto doenças sexualmente transmissíveis (DST). Essas taxas estão elevadas em relação a outros estudos, 5,6 inclusive o de Osasco, 1 em que mais de $40 \%$ das adolescentes do grupo de "grávidas" não usou nenhum método anticonceptivo na primeira relação. Não se pode esquecer que essas respostas podem ter influência do que o jovem sabe ser mais aceito socialmente e não corresponder à plena realidade. Ambos os gêneros referiram que o maior responsável por levar o condom foi o rapaz, demonstrando que os papéis sociais já estabelecidos parecem predominar na prática desses jovens. Entre os principais motivos para o não uso do condom, foram alegados: não ter na hora (28\%) ou confiar no parceiro $(25 \%)$. Feliciano 7 e Garcia 8 demonstraram que a negociação para o sexo seguro está vinculada ao desejo do gênero masculino e que, na presença do afeto, essa negociação torna-se ainda mais difícil. $\mathrm{Na}$ pesquisa com adolescentes de Recife, as variáveis que permaneceram associadas ao uso de condom, na análise multivariada, foram o sexo masculino ( $p=0,029)$, relacionamento com parceiro mais velho $(p=0,002)$ e intervalo de dois a três anos desde a iniciação sexual ( $p=0,017)$.

Portanto, a pesquisa em Recife, apesar de realizada em região geográfica e econômica bastante distinta de Osasco, São Paulo, além das diferenças em relação ao sexo, condição sócio-cultural e financeira, também demonstrou que o nível de conhecimento informado pelos entrevistados sobre prevenção para gravidez foi maior do que a atitude na prática, o que corrobora para a possibilidade de gestação precoce e DST/Aids. Além disso, as vivências e concepções pareceram marcadas por diferenciais de gênero.

É incontestável que as concepções e vivências dos jovens são fundamentais para estratégias de prevenção no plano da sexualidade. Assim, reiteramos as palavras dos colegas de Osasco quanto à necessidade de pesquisas com outros desenhos que permitam um aprofundamento nas representações que influenciam a tomada de decisão das práticas de sexo mais seguro. Nessa perspectiva, é possível 
contribuir para o redirecionamento das estratégias de Saúde Pública na prevenção da gravidez precoce, de DST, para mudanças na qualidade de vida e para o futuro das gerações.

\section{Elizabeth Cordeiro Fernandes 1 \\ Ana Laura Carneiro Gomes Ferreira 2 \\ Tânia Moisa da Silva Marinho 3}

1-3 Instituto de Medicina Integral Prof. Fernando Figueira - IMIP. Rua dos Coelhos, 300. Boa Vista. Recife, PE, Brasil. E-mail: betlui@hotlink.com.br

\section{Referências}

1. Faisal-Cury A, Menezes PR. Sexual activity among female teenagers: acomparison between two groups of middle class adolescents from a private clinic according to pregnancy status. Rev Bras Saúde Matern Infant. 2008 8: 251-6.

2. Marinho TMS. Concepções e práticas relacionadas à sexualidade de adolescentes atendidos em ambulatório de referência no Nordeste do Brasil [dissertação]. Recife: Instituto de Medicina Integral Prof. Fernando Figueira, IMIP; 2008.

3. Bozon M, Heilborn ML. Iniciação à sexualidade: modos de socialização, interações de gênero e trajetórias individuais. In: Heilborn ML, Aquino EML, Bozon M, Knauth DR. O aprendizado da sexualidade. Reprodução e trajetórias sociais de jovens brasileiros. Rio de Janeiro: Garamond Ed. Fiocruz; 2006. p. 156-205.

4. Rieth F. A iniciação sexual na juventude de mulheres e homens. Horiz Antropol. 2002; 8: 77-91.
5. Juarez F, Castro MT. Safe sex versus safe love? Relationship context and condom use among male adolescents in the favelas of Recife, Brasil. Arch Sex Behav. 2006; 35: 25-35.

6. Teixeira AMFB, Knauth DR, Fachel JMG, Leal AF. Adolescentes e uso de preservativos: as escolhas dos jovens de três capitais brasileiras na iniciação e na última relação sexual. Cad Saúde Pública. 2006: 22: 1385-96.

7. Feliciano K. Prevenção de AIDS entre os jovens: significados das práticas e os desafios à técnica. Rev Bras Saúde Matern Infant. 2005; 5: 429-38.

8. Garcia SM. Conhecer os homens a partir do gênero e para além do gênero. In: Arilha M, Ridenti SGU, Medrado B. (organizadores). Homens e masculinidades: outras palavras. São Paulo: ECOS; 1998. Ed 34. p. 31-50.

Recebido em 27 de novembro de 2008

Versão final apresentada em 10 de março de 2009

Aprovado em 13 de março de 2009 